\title{
Mentorship programmes in public primary schools: Beginner teachers' perspectives.
}

\author{
Nerissa Zoutendijk ${ }^{1}$, Anthony Mpisi \\ University of Johannesburg, South Africa
}

\begin{abstract}
Many beginner teachers experience the transition from student teacher to beginner teacher as challenging and a huge reality shock. These adapting demands are often daunting and they therefore need assistance to navigate the transition. The researchers argue that mentorship programmes can assist in addressing these transition challenges. The study makes the point that literature on teacher mentorship in South Africa has largely been from the perspective of administrators, designers and providers of mentorship programmes, rather than from the perspective of the beginner teachers themselves. The aim of the study was therefore to ascertain the perception of beginner teachers in public primary schools in the Ugu district of KwaZuluNatal, South Africa, on mentorship programmes. The study was framed within the constructionist theoretical framework and made use of the qualitative approach, using structured interviews as a data collection instrument. The study revealed that beginner teachers experienced challenges with administration, classroom management and adjusting to the school environment. The findings further revealed that existing informal mentorship programmes failed to adequately address these challenges and meet beginner teachers' professional needs. The researchers, however, argue that formal and welldesigned mentorship programmes potentially have the ability to address the challenges beginner teachers encounter.
\end{abstract}

Key words: Mentorship programmes, public schools, beginner teachers

\section{Introduction}

When first joining the teaching profession, beginner teachers find themselves having to bridge the disjuncture between theoretical knowledge and practice (Esau \& Maarman 2017). Part of the beginner teachers' responsibilities include their involvement in specialising in a particular learning area, subject or phase; specialising in teaching, learning and assessment; curriculum development; leadership, administration and management; lifelong learning; professionalism and involvement in community development, citizenship education, and pastoral care (Department of Education [DoE] 2007). Hence, beginner teachers perceive themselves as unprepared and struggle to cope with all these professional tasks, especially since most initial teacher education (ITE) programmes gravitate more towards theoretical knowledge, as opposed to practical classroom experience (Esau \& Maarman 2019). Consequently, their perceived unpreparedness may contribute to challenges such as workload imbalance, emotional fatigue, physical illness, poor acclimatisation to school culture, and substandard administration (Smit \& du Toit 2016). The latter may in turn lead to frustration and burnout, which results in these teachers' non-performance and even high attrition rate (Engvik 2016).

Befittingly, mentorship programmes have also been employed internationally, in an attempt to aid beginner teachers with their perceived unpreparedness (Harfitt 2014). If employed effectively, mentorship programmes are intended to enlist the support of experienced teachers to assist in diminishing anxiety, fostering workload balance, timetabling execution, combating fatigue, school culture acclimation, quality administrative practices and teaching application of the beginner teacher (Botha \& Rens 2018). In this regard, Arends \& Phurutse (2009) posits that there is a positive correlation between beginner teachers' attrition rate and mentorship programmes. This means that the more effective the mentorship programme, the lower the attrition rate. In South Africa, however, there seems to be a gap in research regarding beginner teachers' perceptions on mentorship programmes (Majocha, Costa, Mpeta, Ara, Whalen \& Fernandes 2017). Hence the researchers argue that literature on teacher mentorship in South Africa has largely been from the 
perspective of administrators and those who design and provide mentorship programmes, rather than from the perspective of the primary beneficiaries themselves (Kadenge 2021).

The article draws strongly on the insight from the lived experiences of beginner teachers themselves, regarding the challenges, strengths, weaknesses and level of support provided from informal mentorship programmes implemented in public primary schools in the Ugu district of KwaZulu-Natal. The findings of this study may serve as a motivation for schools to realise the value of carefully conceived mentorship programmes, and to consider implementing such programmes.

\section{Problem statement}

Most beginner teachers join the teaching profession with passion and enthusiasm, but in most instances this optimism is abruptly curtailed because of the unrealistic expectations of the profession, often without adequate support. Therefore, the introduction of a formal and well-structured mentorship programme could be a possible strategy to support beginner teachers during the first five years of their careers (Majocha et al. 2017, McCollum 2014, Mukeredzi, Mthiyane \& Bertram 2015). It is against the aforementioned backdrop that the study sought to identify the perceived challenges encountered by beginner teachers in public primary schools in the Ugu district of KwaZulu-Natal. Additionally, the study sought to determine the strengths and weaknesses of informal mentorship programmes used to support these teachers.

\section{Beginner teachers}

The concept "beginner teacher" has different meanings to different people. Similarly, the context in which the concept is used can also have an influence on its meaning. According to Spătărelu (2020), and Rhodes (2017), the concept "beginner teacher" generally refers to teachers in their first five years in the teaching profession. In South Africa, however, it is widely accepted that a beginner teacher is a teacher who has recently graduated with a teaching qualification and has been in the profession for under three years (Harmsen, Helms-Lorenz, Maulana, \& van Veen 2018, Smit \& du Toit 2016). In keeping with the variation of contextual meaning, a beginner teacher can also refer to those teachers who have re-entered the teaching profession after five years of absence. The latter may also include foreign nationals teaching in South Africa and other countries for the first time (Brock \& Grady 2007). For the purpose of this study, the concept of beginner teachers refers to teachers who had recently graduated from higher education institutions (HEI) and who were in their first three years of teaching.

\section{Challenges experienced by beginner teachers}

Many beginner teachers experience the transition from student teacher to beginner teacher as challenging and a huge reality shock (Huber \& García 2020, Voss \& Kunter 2020). Ngwira and Potokri (2019) posit that key challenges that beginners experience are environmental by nature and are rooted in the school conditions or teaching profession culture as the place of work. Since each school has a unique school culture, beginner teachers need assistance in acclimating to that culture. Hence, adapting to the new school culture and finding one's place and role within the staff contingent can be an intimidating encounter (Mestry, Hendricks \& Bisschoff 2009). Therefore, adapting is important, as it makes beginner teachers feel less isolated, as part of a team, and enables them to understand where they fit in (Kutsyuruba, Godden, Covell, Matheson \& Walker 2016).

These adapting demands can often prove to be daunting for beginner teachers and therefore they need assistance (Hugo 2018). According to Hugo (2018), and Robinson and Rusznyak (2020) the support offered to beginner teachers seems to be neglected in South Africa. It therefore remains important that beginner teachers are adequately supported, because, if left unattended, the situation could have numerous consequences, such as an increase in the attrition rate amongst beginner teachers (Clandinina, Longa, Schaeferb, Downeyc, Steevesa, Pinnegara \& Wnuka 2015, Dolan 2019).

Concomitant to the above, beginner teachers also experience physical, mental and emotional exhaustion from having to cope with career anxiety, meeting school and professional expectations, finding a balance between their work and their personal lives, as well as the isolation that is synonymous with the initial teaching years (Harmsen et al. 2018, Hugo 2018). Moreover, factors such as learner behaviour, classroom 
management, administration management, and lack of resources are further challenges that beginner teachers encounter (Vikaraman, Mansor \& Hamzah 2017).

Beginner teacher challenges are further compounded by the perceived theoretical, instead of practical, nature of initial teacher education (ITE) programmes. Ebrahim, Verbeek \& Mashiya (2011) argue that ITE programmes, both globally, and in South Africa, seem to place a greater emphasis on the theoretical component than on the practical component. Beginner teachers find it challenging to implement theoretical pedagogy in real life classroom settings. (Emre-Akdoğan \& Yazgan-Sağ 2019, Joseph 2019). In South Africa, student teachers are required to participate in a formally supervised and graded work integrated learning (WIL) for a minimum of 20 weeks for the BEd programme (MRTEQ 2015). These WIL sessions are designed to provide student teachers with school based experience, where students are expected to teach lessons, observe lessons presented by professional teachers, and reflect on lessons in the actual classroom context (Robinson \& Rusznyak 2020). Although literature regards the time spent on WIL as beneficial, Du Plessis (2013), Esau and Maarman (2019), and Hugo (2018) reason that the aforementioned is insufficient to fully acquaint the beginner teacher with the prerequisite skills. These skills relate to applied pedagogical knowledge, pedagogical content knowledge, administration, and classroom management. As a result, beginner teachers need support and guidance to acquire the lacking skills, as well as to make the critical nexus between the theoretical and practical components of ITE programmes (Dawson \& Shand 2019). In this regard, Aspfors and Fransson (2015) posit that formally designed mentorship programmes may serve as a possible approach to support beginner teachers to adequately adapt to the profession.

According to the National Framework for Teacher Education and Development in South Africa (DoE, 2007) and MRTEQ (2015), as mentioned earlier, beginner teachers are required to specialise in a particular learning area, subject or phase; specialise in teaching, learning and assessment; curriculum development; leadership, administration and management; lifelong learning; professionalism; and involvement in community development, citizenship education, and pastoral care. Furthermore, beginner teachers are also expected to adapt to the school culture, meet professional expectations and perform extracurricular activities (Dolan 2019, Sasser 2018).

\section{Mentorship programmes}

The concept "mentor" is broad and can have different meanings for different people. For the purpose of this study the researchers regard the concept "mentor" as an individual who provides assistance to newly graduated teachers (Bleach 1999). In the context of the study, mentorship is equally encompassing, as it focuses on the beginner teachers' needs to be supported and reassured, to be listened to, to be assessed, and also to be reflected with, be flexible, approachable and offer time, as well as commitment to beginner teachers. Furthermore, Hopper (2001) theorises that the mentor also serves as a critical friend, a role model, an assessor, and a counsellor. Hence, a mentorship programme is therefore a sequence of formally arranged activities by the school management team (SCHOOL MANAGEMENT TEAM) that encapsulates the aforementioned in an attempt to assist beginner teachers when they first join the teaching profession. Suitably, Sedibe (2014) regards the mentorship programme as a journey of cooperative work that guides the beginner teacher from dependence to independence.

In the South African setting, the school management team (SMT) comprises the school principal, deputy principal(s) and heads of departments. The role of the SMT is to provides support and guidance to the beginner teacher in areas such as skills development, school policies and administration, resource management, wisdom, and overall guides personal and professional growth (Majocha et al. 2017, Mukeredzi et al. 2015). The primary objectives of mentorship programmes are to provide support to beginner teachers through bridging the divide between theory and practice, to promote professional development, and to support self-actualisation (Harmsen et al. 2018, Vikaraman, et al. 2017).

Many schools, especially in South Africa, have an induction programme for newly appointed teachers. According to Vikaraman et al. (2017), an induction programme is a staff orientation activity that is implemented from the onset of the beginner teacher's career at a school. It summarises the orientation and socialisation of the beginner teacher to the new school (Vikaraman et al. 2017). The researchers argue that the fundamental difference between an induction and mentorship programme resides in the fact that the 
former is more short term, while the latter is long term and has a relationship building dimension. The researchers therefore argue that a mentorship programme, instead of an induction programme, is better suited to support beginner teacher's adjustment needs to the profession. The participant of this study underwent an informal mentorship programme.

In keeping with the aforementioned, the literature reports on the positive effect that mentorship programmes could have on beginner teachers. The positive effects include self-actualisation, self-confidence, increased problem-solving skills, improved classroom management, as well as enhanced teaching and learning (Hobson 2009, Kutsyuruba et al. 2016, Majocha et al. 2017, McCollum 2014). Likewise, mentorship programmes have been found to assist in decreasing challenges faced by beginner teachers, thus increasing beginner teacher professional development, learning, growth and retention (Wolhuter 2014). Correspondingly, Hugo (2018) claims that there is a positive correlation between inefficient mentorship programmes and beginner teacher attrition rates. Subsequently, McCollum (2014) advises that for any mentorship programme to succeed, there must be an intelligible purpose, motivation, and clear roles and responsibilities for both the mentor and the beginner teacher.

By the same token, in South Africa, the Department of Basic Education (DBE) acknowledges that the ineffectiveness of mentorship strategies could lead to poor beginner teacher adjustment (DoE 2007). Henceforth, the New Teacher Induction Guidelines for the Orientation Programme booklet (DBE 2011) outlines the guidelines for conducting an orientation programme for beginner teachers. While the aforementioned legislation provides information on induction and the importance of mentorship strategies, there are no official mandatory mentorship programmes implemented in South African schools (Botha \& Rens 2018, Mukeredzi et al. 2015). The need for this study is further endorsed, since mentorship in South Africa is unregulated, informal and so the experiences of being mentored are diverse. It is therefore critical to establish mentorship programmes from the perspective of the beginner teacher.

Correspondingly, in instances where mentorship programmes are implemented at schools, they are generally implemented in an unstructured and unofficial manner, with hardly any role clarification for either mentors or beginner teachers (Du Plessis 2013, Hugo 2018). Likewise, scholars such as Esau and Maarman (2019), Hugo (2018), and Mukeredzi et al. (2015), claim that ineffective mentorship programmes have the potential of resulting in beginner teachers having poor knowledge of school and department procedures, administrative requirements, use of resources, and a lack of classroom management skills. Lindgren (2007), however, warns that it is not only the presence of a mentorship programme that is critical, but the efficiency and effectiveness thereof.

To summarise, the literature has highlighted the criticality of effective mentorship programmes in assisting beginner teachers to successfully adjust to the profession. The literature has also emphasised the key difference between an induction programme, that is mostly used in South African schools, and a mentorship programme, that is either nonexistent in schools or implemented in an ad hoc and nebulous fashion.

\section{Research question}

The study was guided by the following research question: What are the perceptions of beginner teachers with regards to the mentorship programmes they were exposed to?

\section{Method}

The study explores the perceptions of beginner primary school teachers, in Ugu district of KwaZulu-Natal, South Africa, with regards to mentorship programmes they were exposed to. A qualitative research design couched in social constructivist theoretical framework was used to realise the objective of the study. Qualitative research is a form of social action that focuses on the way humans interpret and make sense of their experiences to understand the social reality of individuals (Mohajan 2018). The qualitative approach was therefore best suited for the study, as the researchers' objective was to interpret and make sense of beginner teachers' reality of how they perceived mentorship programmes. A Constructivist theoretical framework implies "multiple realities constructed by different groups of people and the implications of those constructions for the lives and interactions of others" (Peterson 2019). The elected theoretical framework thus allowed the researchers to yield multiple realities, since beginner teachers subjectively constructed 
meaning of their perceptions of mentorship programmes in their respective schools, by responding to the interview questions.

Participants' interpretations and understandings of their own first-hand experiences on mentorship programmes were collected (Merriam 2009). The study employed purposive sampling that included seven beginner teachers from four public primary schools in the Ugu district of KwaZulu-Natal. The selected teachers therefore had to be in their first to third year of teaching, as per the definition of the concept provided for beginner teachers earlier for the purpose of this study. The seven teachers were selected because of their close geographical proximity to the researcher and had all undergone the same mentorship programme. Permission was sought from the KwaZulu-Natal Education department, school principals, and the participants. The table below summarises the contextual data of the seven participants that participated in the study. For the purpose of this study, the participants were allocated letters, and the primary schools numbers, as pseudonyms in order to protect their confidentiality.

\section{Table 1: Participant information}

\begin{tabular}{|c|c|c|c|c|c|}
\hline Participant & School & $\begin{array}{l}\text { Qualifications } \\
\text { of teachers }\end{array}$ & $\begin{array}{l}\text { Years of teaching } \\
\text { experience as a class } \\
\text { teacher }\end{array}$ & Age of teachers & Gender of teachers \\
\hline 1 & A & PGCE & 3 & $30-39$ years & Male \\
\hline 2 & A & BEd & 1 & $30-39$ years & Male \\
\hline 3 & $\mathrm{~B}$ & BEd & 2 & 20-29 years & Female \\
\hline 4 & B & PGCE & 1 & 20-29 years & Female \\
\hline 5 & $\mathrm{C}$ & BEd & 1 & $20-29$ years & Female \\
\hline 6 & $\mathrm{C}$ & BEd & 1 & 30-39 years & Female \\
\hline 7 & $\mathrm{D}$ & BEd & 3 & 20-29 years & Female \\
\hline
\end{tabular}

The researchers elected to use structured interviews as a data collection instrument, comprising of openended questions, as it elicits in-depth thought provoking responses and details regarding participants' feelings (Denzin \& Lincoln 2011). The structured interviews were most suitable, given the COVID-19 restrictions at the time. In keeping with the COVID-19 protocols, the interview schedule was emailed to the participants. The interview schedules were completed, scanned and emailed back to the researcher by participant, thus avoiding any physical contact. Data were analysed through qualitative coding, as it allowed for themes, concepts and correlations to be linked and categorized in a logical way (Merriam 2009).

\section{Findings and discussion}

The main findings of the study are presented in this section. Two main themes emerged while analysing the responses of the beginner teachers, namely beginner teachers' obstacles, and weaknesses of existing mentorship programmes. Table 2 illustrates the themes and sub-themes that emerged during the analysis of the responses provided by the beginner teachers.

Table 2: Research themes and sub-themes

\begin{tabular}{|c|c|c|}
\hline Theme & & Sub-theme \\
\hline & \multirow{3}{*}{$\begin{array}{l}\text { Obstacles experienced by } \\
\text { beginner teachers }\end{array}$} & $\circ \quad$ Administration \\
\hline & & $\circ \quad$ Classroom management \\
\hline & & Working environment \\
\hline & \multirow{3}{*}{$\begin{array}{l}\text { Weaknesses of existing } \\
\text { mentorship programmes }\end{array}$} & $\circ \quad$ Existing mentorship programmes \\
\hline & & $\circ \quad$ Informal nature of mentorship \\
\hline & & $\circ \quad$ Poorly defined roles and responsibilities of mentors \\
\hline
\end{tabular}

\subsection{Findings on theme 1: Obstacles experienced by beginner teachers}

The first theme, obstacles experienced by beginner teachers, revealed three sub-themes, namely administration, classroom management, and the working environment. The aforementioned sub-themes that 
beginner teachers perceived as obstacles, were thought of as impeding their effective adjustment into the teaching profession.

\subsubsection{Administration}

Most participants indicated that they experienced difficulty in knowing what was expected of them regarding school administration. In this respect, one participant pointed out her frustration with the school administration as: "Not knowing what is expected." Participant $1 \mathrm{~A}$ responded by lamenting that "At University we do not learn about all the admin that goes along with leading your own class." Participant 2A agreed with the former, stating that "It is impossible to be fully prepared for the amount of admin that goes along with teaching." The study further exposed that schools failed to provide sufficient guidance, as far as school administration is concerned. "There was no one that helped or offered to help, for two years I did absolutely no filing or admin," was the response of participant 3B. Furthermore, participants complained about the amount of administration that they are required to complete, as indicated by Participant 4B: "I had never done admin such as educator and assessment files before." Participant 5C indicated that "The amount of admin that was involved was truly unbelievable."

The word administration featured in all the four verbatim quotes presented as one of the most challenging areas. The researchers therefore conclude that the lack of preparedness for school administration is a major challenge for these teachers. The nature of the difficulty was made manifest in words such as "impossible" and "unbelievable", used by participants $2 \mathrm{~A}$ and $5 \mathrm{C}$ respectively.

Administration forms an integral part of the teaching profession. It is therefore important for beginner teachers to master this in order to manage their classrooms effectively (Dolan 2019). However, the empirical findings suggest that beginner teachers are experiencing difficulty in satisfying the professional administrative expectations required by the school, as they are not sufficiently guided in this respect (Aspfors \& Fransson 2015). Many participants found this a challenge, as both ITE programmes and schools failed to effectively prepare them for this, and subsequently experienced the amount of administration as unbearable (Dolan 2019).

\subsubsection{Classroom management}

Judging from the findings of the study, it would seem that classroom management is another obstacle beginner teachers are confronted with. For participant $6 \mathrm{C}$, creating an effective learning environment proved to be challenging. To this end she reported that "Getting a routine ... being a new teacher is very much trial and error, so forming a solid routine with a class can take time and a few learning curves." Classroom management also involves learner discipline. In this respect, the findings indicate that beginner teachers indeed found it hard to establish effective classroom discipline, as demonstrated by participant 7D: "I wasn't prepared to deal with behavioural problems. A few classroom management tricks would have been helpful." Participant 2A articulated that "It is a huge challenge when you have your first class to get your own system with discipline...." Participant 5C stated that "In my first year of teaching the learners were disrespectful, ill-mannered, rude and lacked responsibility."

Learner discipline featured prominently in the responses of participants, indicating their unpreparedness to effectively manage their classrooms. Words such as "behavioural problems" and "rude", used by participants 7D and 5C respectively, provide an indication of the extent of the challenges beginner teachers experience in managing learners in their classrooms.

These findings coincide with the views of Dawson \& Shand (2019), who advance that beginner teachers need assistance with classroom management and learner discipline. The majority of the participants expressed that they encountered challenges with classroom management and learner discipline, particularly with formulating disciplinary procedures for disruptive behaviour in their classes. The latter views correspond with that of Vikaraman et al. (2017), indicating that most behavioural issues potentially stem from the absence of clear and concise disciplinary systems for disruptive behaviour.

\subsubsection{Working environment}


Adapting to a new work environment was one more obstacle for beginner teachers. Participant 1A mentioned that, while staff members initially made him feel welcome, when first joining the school, this gesture unfortunately failed to translate into making him truly feel part of the team or providing him with professional assistance. Participant 6C mentioned that "Staff were friendly on the surface, but other than that, no one was very helpful or interested unless they needed something. I was very lonely due to all the cliques and drama among the staff." By the same token, participant $2 \mathrm{~A}$ revealed that "I struggled to see eye to eye with certain staff..." The findings further exposed that internal politics and existing counterproductive school cultures could also adversely affect beginner teachers' adjustment to the working environment. The following response for Participant 3B bears testimony to the latter: "Due to the amount of pressure from management, it created a very negative working environment. Staff were stressed...could not provide support or encouragement to one another...became very despondent and unhappy...I actually stopped enjoying teaching. I was miserable and dreaded going to work every day."

The participants' responses revealed that they failed to experience the working environment as nurturing and supporting. Their choice of words such as "cliques", "struggle" and "unhappy", used by participants 1A, 2A and $3 \mathrm{~B}$ respectively, have negative connotations, suggesting the unpreparedness of beginner teachers for functioning in the authentic working environment.

These findings agree with that of the literature, suggesting that beginner teachers find it difficult to fit in and make real connections with colleagues, as there are already social groups formed and a culture that they are expected to fit into. Congruently, Mestry et al. (2009) point out that many beginner teachers thus seem to experience feelings of loneliness, despondency, and having no support. In this regard Engvik (2016) and Smit \& du Toit (2016) warn that if the aforementioned is left unattended it may ultimately lead to high beginner teachers' attrition. These findings further augment that of the literature which posits that mentorship is an encompassing journey that involves the beginner teachers' needs to be guided and supported, ultimately culminating in independence (Hopper 2001).

\subsection{Findings on theme 2: Weaknesses of existing mentorship programmes}

The second theme, weaknesses of existing mentorship programmes, uncovered three sub-themes that beginner teachers perceived as weaknesses of existing mentorship programmes, namely the existing mentorship programmes, the informal nature of mentorship, and the poorly defined roles and responsibilities of mentors.

\subsubsection{Existence of mentorship programmes}

The findings suggest that mentorship programmes are conducted on an informal or ad hoc basis. The latter is supported by a response from participant 7D: "Although there was a mentorship programme. I had to figure things out for myself as I went along." Participant 3B echoed this sentiment: "To be honest, a mentor was assigned to me but left me to figure it out on my own and wasn't any help." While one participant 6C conceded to having been assigned a mentor, he communicated this experience as follows: "I was formally given a mentor, who met with me once in my first week to show me admin etc. But then she didn't help me afterwards at all." The participants' experience contrasted with the literature that insists that mentoring is "a journey of cooperative work that leads the beginner teacher from dependence to independence" (Sedibe 2014). At least three participants stated that they relied on the knowledge and experience gained during their school visits for WIL, while still student teachers. Participant 5C revealed that "I view my practical teaching period as my very own mentorship programme."

The empirical findings partially agree with the literature, which claims that many beginner teachers in South Africa are not participating in formally structured mentorship programmes (Aspfors \& Fransson 2015, Esau \& Maarman 2017, Smit \& du Toit 2016). The need for mentoring becomes evident from the responses of beginner teachers. Therefore, Botha \& Rens (2018) and Arends \& Phurutse (2009) assert the criticality of mentorship programmes to assist beginners teacher to deal with their unpreparedness to teach.

\subsubsection{Informal mentorship}

From the findings, the researchers concluded that informal mentorship, rather than formal mentorship, is implemented at these schools. Participant 4B stated that "No mentorship, maybe informally at best!." 
Participant 7D responded that "I'm not sure whether one can call it a mentorship programme. I had...still have...a mentor...informally." Participant 6C shared the sentiments of other beginner teachers regarding the informal assistance provided by experienced colleagues. She said that experienced colleagues would only support when asked: "I was given advice in passing or when I asked specific questions or sought out a teacher to ask." The responses by the participants tie in with the literature arguing that formal and wellstructured mentorship programmes could be a possible strategy to support beginner teachers during the first few years of their career (Majocha et al. 2017, McCollum 2014, Mukeredzi et al. 2015).

While the aforementioned views might hold merit, Sasser (2019) advances a totally contrasting interpretation of informal mentorship, postulating that they may hold some benefits, as they are less intimidating for the beginner teachers. Although concurring with Sasser (2019) in part, the researchers argue that benefits of formal mentorship programmes could not be understated. The latter notion is echoed by Steyn \& Van Niekerk (2012) who maintain that the absence of formal mentorship programmes may leave beginner teachers feeling unsupported and abandoned. The researchers therefore insist on the critical role the implementation of formal mentorship programmes can play in easing beginner teacher into the profession.

\subsubsection{Poorly defined mentor roles and responsibilities}

The third sub-theme that beginner teachers perceived as weaknesses of existing mentorship programmes was the roles and responsibilities of mentors. When participant 1A was asked whether his mentor had effectively performed the roles and responsibilities of a mentor, he alluded to the inconsistency of the assistance provided: "Adequately, I knew what to expect, but I also had to find out a lot on my own." At least two participants acknowledged that their mentors executed their mentor roles and responsibilities with distinction. This was, however while one was still a student teacher participating in WIL and the other while serving as an assistant teacher, respectively. Participant 5C explained that "The way I could observe my mentor's teaching made me learn life lessons ... I could see how a school set up functioned, even though still a student teacher." The other respondent, participant 4B, who was still an assistant teacher at the time, articulated her experience then as: "My grade-head was my mentor, she took me under her wing and made sure that I knew what to do and when ... she made sure that I understood my planning ... and helped by showing me how to present lessons." Similarly, participant 3B acknowledged receiving ample support and guidance: "...she has been a brilliant mentor. I have already learned so much from her and she is always on hand to answer any questions that I may have and always checks up on me to see how I am coping and she is always supporting and encouraging."

The direct words used by participants 7D, 3C and 4B, namely "some sort of mentorship programme", as well as participant 5C's "own mentorship programme", suggest that there are weaknesses in mentorship programmes, in instances where they do exist. It is further deduced that school management assumes that beginner teachers are ready to teach, since they are in possession of a teachers' qualification and that they do not need professional assistance to adapt to the profession.

From the responses, it would seem that there are either no clearly delineated roles and responsibilities for mentors, or mentors are not formally held accountable for their mentoring duties. These findings correspond with that of the literature that theorises that the mentorship programmes employed at schools are conducted in an ineffective manner, with barely any role clarification for either mentors or beginner teachers (Du Plessis 2013, Hugo 2018). In keeping with role clarification, Majocha et al. (2017) and Mukeredzi et al. (2015) stress that the role of the mentor, as the experienced teacher, is to guide the beginner teacher towards personal and professional growth.

These findings additionally expose that most beginner teachers seem to have gained more benefit from mentorship while they were either still student teachers or assistant teachers, thereby resulting in the researchers' conclusion that mentor teachers executed their roles and responsibilities more effectively towards student and assistant teachers. This may stem from the perception that mentors regard student and assistant teachers as being more in need of mentoring than beginner teachers.

\section{Findings and recommendations}


Two main themes emerged while analysing the responses on the beginner teachers, namely beginner teachers' obstacles, and weaknesses of existing mentorship programmes.

A summary of the key findings, together with corresponding recommendations are now provided. The first theme that emerged from the findings was "obstacles experienced by beginner teachers." From the latter theme, administration, classroom management and the working environment emerged as sub-themes that impeded the effective adjustment of beginner teachers into the teaching profession. The findings of the study indicated that beginner teachers experienced challenges in managing the administration required from them. The challenge was compounded by their poor understanding of what specifically was expected of them, as well as their inability to manage their time effectively in this regard. Classroom management seemed to pose an equally great challenge to beginner teachers, as it would seem that ITE programmes had failed to sufficiently prepare them for this reality, especially as far as disruptive behaviour from learners is concerned. The working environment was another sub-theme that emerged as an impediment for their conducive adjustment, as collegial relations seemed to be characterised by cliques, internal politics and existing counter-productive school cultures, leaving limited room for mentoring.

The researchers therefore recommend closer collaboration between the Department of Basic Education and universities. In so doing these challenges experienced by beginner teachers could be foregrounded and incorporated into ITE programmes. It is further recommended that the SMTs have a series of professional development workshops, where specific topics on administration, classroom management, and the working environment are addressed in a hands-on manner. Role-play could serve as an effective strategy, as it can involve staff members across all experience categories, and has the added advantage of addressing serious topics in a fun way.

The second theme that the study uncovered was the weaknesses of existing mentorship programmes, existing mentorship programmes, the informal nature of mentorship, and the roles and responsibilities of mentors, emerging as sub-themes. The findings suggest that mentorship programmes are mostly dealt with in a nonchalant and unstructured manner. Some schools have induction programmes, but these hardly yield any effective results, given their short term nature. The findings further revealed that both mentors and beginner teachers were not well versed with their respective roles and responsibilities. Hence, the researchers are recommending that all schools should be held accountable for implementing a mentorship programme, encapsulating common challenges experienced by beginner teachers. The implementation of such a programme should be mandatory, with clearly defined roles and responsibilities circumscribed for both mentors and beginner teachers. Mentoring of beginner teachers should be formally written into the job descriptions of SMT members and they (SMT) should provide official reports on their mentoring duties in official staff meetings.

\section{Conclusion}

The aim of the study was to ascertain the perceived challenges encountered by beginner teachers in primary schools in the Ugu district of KwaZulu-Natal. The study also sought to gain insight into the perceptions of beginner teachers on existing mentorship programmes used to support beginner teachers. The researchers argue that many beginner teachers experience the transition from student teacher to beginner teacher as challenging and therefore need assistance to navigate the transition. The study revealed that mentorship programmes could serve as a possible vehicle to address and potentially minimise these transition challenges. The researchers also argue that, while most that literature on teacher mentorship in South Africa has primarily been viewed from the perspective of designers and providers of mentorship programmes, this study has however managed to provide insight into the lived experiences of beginner teachers during their transition into the teaching profession. These insights, from the beginner teachers' perspectives, may serve to inform policy, practice, and the design of future mentorship programmes. Such future mentorship programmes may succeed in assisting beginner teachers with pertinent challenges they experience, such as administration, classroom management and adjusting to the school environment, when first joining the profession. A future study is envisaged where the guidelines for the design of future beginner-orientated mentorship programme will be explored.

\section{References}

Dr KOFFI Fêtê Ernest, IJSRM Volume 10 Issue 01 January 2022 [www.ijsrm.in]

EL-2022-2155 
1. Arends F, Phurutse M (2009) Beginner teachers in South Africa: school readiness, knowledge and skills. Cape Town: HSRC Press.

2. Aspfors J, Fransson G (2015) Research on mentor education for newly qualified teachers: A qualitative meta-synthesis. Teaching and Teacher Education 48 (1): 75-86.

3. Bleach K (1999) The induction and mentoring of newly qualified teachers. London: Fulton.

4. Botha CS, Rens J (2018) Are they really 'ready, willing and able'? Exploring reality shock in beginner teachers in South Africa. South African Journal of Education 38 (3):1-8

5. Brock BL, Grady ML (2007) Understanding the Beginning Teacher. From First Year to First-Rate: Principals Guiding Beginning Teachers. California: Corwin Press

6. Clandinina DJ, Longa J, Schaeferb CL, Downeyc A, Steevesa P, Pinnegara E, Wnuka S (2015) Early career teacher attrition: intentions of teachers beginning. Teaching Education 26 (1): 1-16.

7. Dawson V, Shand J (2019) Impact of support for preservice teachers placed in disadvantaged schools. Issues in Educational Research 29 (1): 19-37.

8. Denzin NK, Lincoln YS (Eds) (2011) The Sage handbook of qualitative research. Los Angeles: Sage.

9. Department of Education RSA (2007) The National Framework for Teacher Education and Development in South Africa. Pretoria: Government Printer.

10. Department of Education RSA (2008) Mentor school managers \& manage mentoring programmes in schools. Advanced certificate: Education (School management and leadership). Pretoria: Government Printer.

11. Department of Basic Education RSA (2011) New teacher induction: Guidelines for the Orientation Programme. Pretoria: Government Printer.

12. Department of Basic Education and Department of Higher Education and Training RSA (2011) Integrated Strategic Planning Framework for Teacher Education and Development in South Africa 2011-2012. Pretoria: Government Printer.

13. Department of Higher Education and Training RSA (2015) Revised Policy on the Minimum Requirements for Teacher Education Qualifications. Pretoria: Government Printer.

14. Dolan AK (2019) The unsinkable new teacher: A perspective for teacher attrition. The New Hampshire Journal of Education 21 (Fall): 10985.

15. Du Plessis E (2013) Mentoring challenges in the teaching practice of distance learning students. The Independent Journal of Teaching and Learning 8 (1): 1-16.

16. Ebrahim HB, Verbeek DC, Mashiya JN (2011) Enabling roles to reclaim teacher agency: Insights from the Advanced Certificate in Teaching (Foundation Phase). Perspectives in Education 29 (4): 58-65.

17. Emre-Akdoğan E, Yazgan-Sağ G (2019) Transformation of theoretical knowledge into instructional practice: A mathematics teacher's journey. Issues in Educational Research 29 (1): 55-69.

18. Engvik G (2016) The school's professional culture as a basis for guidance and learning in teachers' first working year. In: Ostern AL, Engvik G (Eds) Guided practices in the movement, school, education, arts. Bergen: Fagbokforlaget.

19. Esau DE, Maarman RFA (2017) Exploring beginner teachers' perceptions of school support to enhance their capability sets in relation to teacher education policy. Doctoral Thesis, South Africa: University of the Western Cape.

20. Esau DE, Maarman RFA (2019) Re-positioning the competences of beginner teachers in South Africa: A capabilities perspective. South African Journal of Higher Education 33 (6): 111-132.

21. Harfitt G (2014) From attrition to retention: a narrative inquiry of why beginning teachers leave and then rejoin the profession. Asia-Pacific Journal of Teacher Education 43 (1): 22-35.

22. Harmsen R, Helms-Lorenz M, Maulana R, van Veen K (2018) The relationship between beginning teachers' stress causes, stress responses, teaching behaviour and attrition. Teachers and Teaching 24 (6): 626-643.

23. Hobson AJ (2009) On being bottom of the pecking order: beginner teachers' perceptions and experiences of support. Teacher Development 13 (4): 299-320.

24. Hopper B (2001) The role of the HEI tutor in initial teacher education school-based placement, Mentoring \& Tutoring. Open access journal 9 (3): 211-222. 
25. Huber GL, García CM (2020) Voices of beginning teachers: Computer-assisted listening to their common experiences. In: Michael Schratz Qualitative voices in educational research. London: Routledge, 139-156.

26. Hugo J (2018) The development and implementation of an effective mentoring programme to improve job satisfaction among beginner teachers at primary schools in the Mpumalanga Province of South Africa. Doctoral Thesis,South Africa: UNISA.

27. Joseph D (2019) "Trying to keep afloat": Early career teaching in an Australian setting. Issues in Educational Research 29 (2): 444-457.

28. Kadenge E (2021) A district beginner teacher induction initiative in South Africa: The pressure and support contestation. Perspectives in Education 39 (3): 214-227.

29. Kutsyuruba B, Godden L, Covell L, Matheson I, Walker K (2016) Understanding the Contextual Factors Within Teacher Induction and Mentoring Programs: An International Systematic Review of Research. Kingston: Queens University Press.

30. Lindgren U (2007) Experiences of beginning teachers in a school-based mentoring program in Sweden. Educational Studies 31 (3): 251-263.

31. Majocha EF, Costa MAM, Mpeta M, Ara N, Whalen CA, Fernandes TA (2017) Sustaining growth of novice teachers to leadership through mentorship process: A study of praxis in Brazil, Canada, Pakistan, and South Africa. In: Miller P (Ed) Cultures of Educational Leadership. Intercultural Studies in Education. London: Palgrave Macmillan, 95-219.

32. McCollum I (2014) Beginning Teachers' Perceptions of a Teacher Mentoring Program. Doctoral Thesis, USA: Walden University.

33. Mestry R, Hendricks I, Bisschoff T (2009) Perceptions of teachers on the benefits of teacher development programmes in one province of South Africa. South African Journal of Education 29 (4): 475-490.

34. Merriam S (2009) Qualitative research: A guide to design and implementation. San Francisco: John Wiley \& Sons.

35. Mohajan HK (2018) Qualitative research methodology in social sciences and related subjects. Journal of economic development, environment and people 7 (1): 23-48.

36. Mukeredzi TG, Mthiyane N, Bertram C (2015) Becoming professionally qualified: The school-based mentoring experiences of part-time PGCE students. South African Journal of Education 35 (2): 1-9.

37. Ngwira H, Potokri OC (2019) Induction of Women Beginner Teachers At Two South African Community Secondary Schools. Problems of Education in the 21st Century 77 (6): 774.

38. Peterson JS (2019) Presenting a qualitative study: A reviewer's perspective. The gifted child quarterly 63 (3): 147-158.

39. Rhodes R (2017) Supporting novice teachers: Peer coaching and collaborative inquiry as support. Georgia: Kennesaw State University.

40. Robinson M, Rusznyak L (2020) Learning to teach without school based experience: conundrums and possibilities in a South African context. Journal of Education for Teaching 46 (4): 517-527.

41. Sasser A (2018) Novice Teachers' Perception of Mentoring and Teacher Retention. Doctoral thesis, USA: Georgia Southern University.

42. Sedibe M (2014) Exploring Student Teachers' Perceptions on Mentoring during School Experience at High Schools in Gauteng Province, South Africa. Journal of Educational and Social Research 4 (3): 197.

43. Smit T, du Toit PH (2016) Transforming beginner teacher mentoring interventions for social reform. South African Journal of Education 36 (3): 1-12.

44. Spătărelu E (2020) Beginner Teacher in the Recent Research: A Review of Literature. Journal of Education Studies 2 (2) 107-122.

45. Steyn G, Van Niekerk E (2012) Human Resource Management in Education. Pretoria: Van Schaik.

46. Vikaraman SS, Mansor AN, Hamzah MIM (2017) Mentoring and coaching practices for beginner teachers - a need for mentor coaching skills training and principal's support. Creative Education 8 (1): 156-169.

47. Voss T, Kunter M (2020) "Reality shock" of beginning teachers? Changes in teacher candidates' emotional exhaustion and constructivist-oriented beliefs. Journal of Teacher Education 71 (3): 292306. 
48. Wolhuter C (2014) Weaknesses of South African education in the mirror image of international educational development. South African Journal of Education 34 (2): 1-25.

Nerissa Zoutendijk holds a Masters' degree in Educational Leadership and Management from the University of Johannesburg and is a primary school teacher in KwaZulu- Natal. nzoutie@gmail.com

Anthony Mpisi holds a PhD in the Psychology of Education and is a senior lecturer in the School of Education, Sol Plaatje University, Kimberley, South Africa. He has delivered several chapters at national, as well as international conferences, contributed to textbook chapters, and has published in accredited journals as well. tony.mpisi@spu.ac.za 